2003-01-01

\title{
Improved Pattern Stability for Monopole Antennas with Ultrawideband Impedance Characteristics
}

\author{
Max Ammann \\ Technological University Dublin, max.ammann@tudublin.ie
}

Follow this and additional works at: https://arrow.tudublin.ie/engschececon

Part of the Electrical and Computer Engineering Commons

\section{Recommended Citation}

Ammann, M. (2003) Improved pattern stability for monopole antennas with ultrawideband impedance characteristics. IEEE Antennas and Propagation Society International Symposium, pp.818-821. Columbus, Ohio, USA, 22-27 June, 2003, doi:10.1109/APS.2003.1217586

This Conference Paper is brought to you for free and open access by the School of Electrical and Electronic Engineering at ARROW@TU Dublin. It has been accepted for inclusion in Conference papers by an authorized administrator of ARROW@TU Dublin. For more information, please contact arrow.admin@tudublin.ie, aisling.coyne@tudublin.ie,gerard.connolly@tudublin.ie.

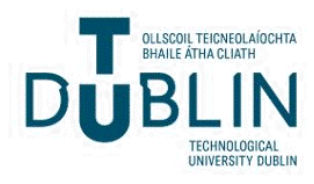




\title{
IMPROVED PATTERN STABILITY FOR MONOPOLE ANTENNAS WITH ULTRAWIDEBAND IMPEDANCE CHARACTERISTICS
}

\author{
M. J. Ammann \\ School of Electronic \& Communications Engineering \\ Faculty of Engineering \\ Dublin Institute of Technology, \\ Kevin St., Dublin 8, Ireland
}

INTRODUCTION

Future software defined and reconfigurable radio networks are required to operate in multiple, wide-ranging, frequency bands, which place heavy demands on antenna designs. Rather than using antennas tuned to operate in certain predefined frequency bands under predefined radio systems at the time of manufacture, which limits the possibilities of implementing new radio systems on a reconfigurable terminal, a wideband antenna is proposed. The use of a single antenna which can operate over many octaves is very desirable for future wireless communications systems.

BACKGROUND

The planar monopole has recently been investigated as an antenna with very wideband properties. Much work has been carried out since the antenna was first reported by Dubost and Zisler in 1976. [1]. Planar disc monopole antennas have been researched [2] and proposed for use in the Japanese television band [3]. The dependency of impedance bandwidth on feedgap separation has been noted [4] and an optimised shorted planar monopole with bevel which has an impedance bandwidth (2:1 VSWR) from $800 \mathrm{MHz}$ to $11 \mathrm{GHz}$ has been reported. [5]. The addition of a bevel on one side of the planar geometry was shown to increase the bandwidth with good control of the upper edge frequency. For ultrawideband communications, the FCC allocated frequency band is $3.1 \mathrm{GHz}$ to $10.6 \mathrm{GHz}$ and this is not limited to pulse type UWB. Hence, the time domain parameters of the antenna are not of concern in this paper.

IMPEDANCE BANDWIDTH

The simple square planar monopole (SPM) has been shown to have an impedance bandwidth of $75.80 \%[4]$ and the addition of a shorting post [6] increases this to about $110 \%$. The addition of a bevel on the opposite side to the shorting post is necessary to provide a 10:1 impedance bandwidth ratio. The bevel increases the upper edge frequency, and control of this frequency is possible by choice of bevel angle [7]. Circular and elliptical disc monopoles also have very wide impedance bandwidths but with poor control of upper edge frequency. In this case, the dimension, $L$, of the simple square planar monopole is $20 \mathrm{~mm}$, and the VSWR is less than $2: 1$ from $2.4 \mathrm{GHz}$ to $6.9 \mathrm{GHx}$. The 
addition of a $20^{\circ}$ bevel (SPMB) as shown in Figire 1 increases the upper edge frequency to $10 \mathrm{GHz}$, which is appropriate for UWB communications.

\section{RADIATION PATTERNS}

Radiation patterns have been reported over a range of frequencies for these antennas, and although the patterns are quite stable over the impedance bandwidth of the simple square element (typically, $75 \%$ fractional impedance bandwidth), the pattern stability becomes a problem when the bandwidth is more than a few octaves, as is the case for ultrawideband elements. Noticeable variations in radiation pattern with frequency have been shown [8]. This occurs because the planar element dimension changes from about 0.2 of a wavelength at the lower edge frequency to about 1.5 wavelengths at the upper edge frequency. Also, if a shorting post is employed, the asymmetry also affects the stability.

\section{ANTENNA AUGMENTATION}

To improve the radiation pattern stability with change of frequency, the planar element was modified and the radiating element comprised two elements orthogonal to each other and referred to in this paper as the crossed planar monopole (CPM). These are shown in Figure 1 along with the coordinate system employed. The antennas are constructed using $0.2 \mathrm{~mm}$ thick copper sheet on a $100 \mathrm{~mm}$ square groundplane and fed using an SMA connector. The height of the planar element, $h$, is $20 \mathrm{~mm}$ and a feedgap separation, $g$, of 2.0 $\mathrm{mm}$ is used. The return loss was greater than $10 \mathrm{~dB}$ from $2.7 \mathrm{GHz}$ to approx. $10 \mathrm{GHz}$ for a bevel angle $\alpha=20^{\circ}$. The changes made to the geometry had little effect on the impedance bandwidth.

\section{RADIATION PATTERN ENHANCEMENT}

The E plane patterns for the planar monopole antenna are typically monopolar with a deep null ( $30 \mathrm{~dB})$ at $\theta=0^{\circ}$. The main variation with frequency is that the beam of maximum gain is raised from the plane of the groundplane as the frequency increases. (ie from $\theta=70$ to $\theta=45$ or so). The E-plane patterns have been reported for various elements and are not discussed here $[5,6,8]$. A greater challenge is maintaining an omnidirectional pattern in the H-plane, over the UWB bandwidth

The H-plane patterns $E_{\theta}(\phi, \theta=90)$ are illustrated in Figure 2. Radiation patterns have been measured at $2.4 \mathrm{GHz}, 4.8 \mathrm{GHz}, 6.8 \mathrm{GHz}$ and $9 \mathrm{GHz}$ for the bevelled planar monopole and the crossed planar monopole: The patterns at $2.4 \mathrm{GHz}$ were purely omnidirectional for both antennas and for brevity are not shown here. However, it can be seen that the bevelled planar monopole exhibits distortion in the pattern, particularly at the higher frequencies. In contrast, the pattens for the crossed planar monopole remain very stable with frequency. The patterns are normalised to maximum gain, which is typically about $4.3 \mathrm{dBi}$ at the lower frequencies and increases with frequency to about $6.0 \mathrm{dBi}$. The 
variations are shown in Table 1 , which gives the maximum variation from the normalised maximum gain in the $\mathrm{H}$-plane for both antennas.

\begin{tabular}{|c|c|c|}
\hline \multicolumn{3}{|c|}{ Largest deviation from maximum gain in $\mathrm{H}$-plane $(\mathrm{dB})$} \\
\hline & Planar monopole & Crossed monopole \\
\hline $4.8 \mathrm{GHz}$ & 3.0 & 1.1 \\
\hline $6.8 \mathrm{GHz}$ & 5.7 & 2.2 \\
\hline $9.0 \mathrm{GHz}$ & 9.3 & 2.8 \\
\hline
\end{tabular}

Table 1

\section{CONCLUSIONS}

The addition of a second planar element orthogonal to the planar monopole improves the radiation pattern stability without degrading the ultrawideband impedance characteristics

\section{REFERENCES}

1. Dubost, G. and Zisler, 1976, Antennas a Large Bande, Masson, Paris, New York, pp.128-129.

2. Agrawall, P. A., Kumar, G. and Ray, K., 1998, Wideband Planar Monopole Antennas, IEEE Trans. Antennas \& Propagat. AP-46, (2), 294-295.

3 Honda, S. et al. 1992, A disk monopole antenna with 1:8 impedance bandwidth and omnidirectional radiation pattern, Proc. ISAP, Sapporo, Japan, $1145-1148$.

4. Ammann, M. J., 'Square Planar Monopole Antennas' 1999, IEE NCAP, 37 40.

5. Ammann, M. J and Chen, Z. N, 2003, A Wideband Shorted Planar Monopole with Bevel', IEEE Trans. Antennas \& Propagat, AP-51 (3), to be published March 2003.

6. Lee, L.S., Hall, P.S. and Gardner, P., 'Compact wideband planar monopole antenna' Electron Lett. 1999, (35), 2157-2158.

7. Ammann, M. J., 'The pentagonal planar monopole for digital mobile terminals: bandwidth considerations and modelling,' 2001, $11^{\text {th }}$ IEE ICAP, (1), 82-85.

8. Ammann, M. J.,'A Wideband Monopole For Reconfigurable Multiband Radio Terminals' IEEE International Antennas \& Propagat. Symp. (Digest), 2001 (1), 170-173.
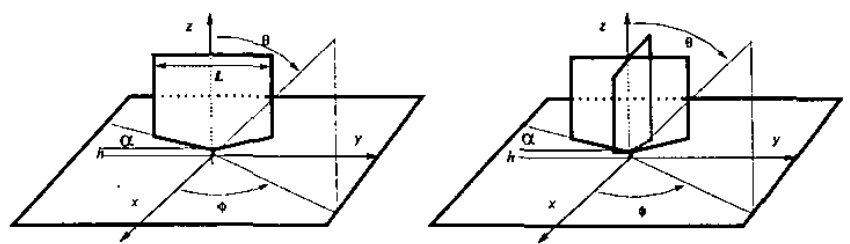

Figure 1. The square planar monopole with bevel (SPMB) and the crossed planar monopole (CPM) geometry and coordinate system 

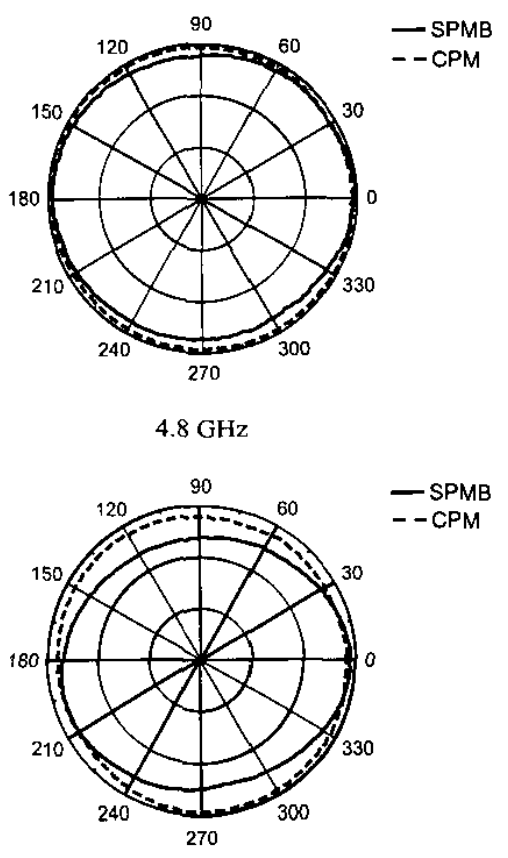

$6.8 \mathrm{GHz}$

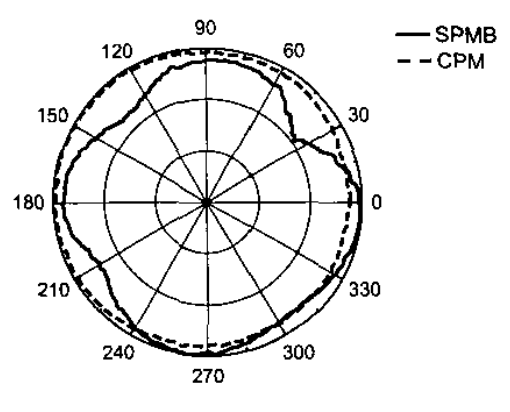

$9 \mathrm{GHz}$

Figure 2. H-plane radiation patterns $E_{\theta}(\phi, \theta=90)$ for the antennas at $4.8,6.8$ and $9 \mathrm{GHz}$.

821 